\title{
Produtividade e conservação de cebola afetadas pela adubação nitrogenada no sistema de plantio direto
}

\author{
Claudinei Kurtz ${ }^{1,3}$; Paulo R Ernani²; Volnei Pauletti ${ }^{3}$ Francisco O Gervini de Menezes Junior ${ }^{1}$; João \\ Vieira Neto ${ }^{1}$ \\ 'EPAGRI, Lageado Águas Negras, C. Postal 121,88400-000 Ituporanga-SC; kurtz@epagri.com.br; franciscomenezes@epagri.sc.gov.br; \\ joaoneto@epagri.sc.gov.br; ${ }^{2}$ UDESC-CAV, Depto. Solos, C. Postal 281, 88520-000, Lages-SC; prernani@cav.udesc.br; ${ }^{3}$ UFPR, Progr. \\ Pós-graduação em Ciência do Solo, R. dos Funcionários 1540, 80035-050 Curitiba-PR
}

\section{RESUMO}

O rendimento e a conservação da cebola são influenciados pela disponibilidade de nitrogênio $(\mathrm{N})$ no solo. No presente trabalho avaliou-se o efeito de doses e do número de aplicações de $\mathrm{N}$ em cobertura no desenvolvimento, no estado nutricional das plantas, no rendimento e na conservação pós-colheita de bulbos de cebola cultivada no sistema de manejo do solo com plantio direto. Foram realizados três experimentos em campo, sobre um Cambissolo Háplico Distrófico de textura média, em Ituporanga-SC. Os tratamentos consistiram de uma combinação fatorial $(4 \times 3)$ envolvendo quatro doses de $\mathrm{N}\left(0,50,100\right.$ e $\left.200 \mathrm{~kg} \mathrm{ha}^{-1}\right)$ e três modos de parcelamento da dose de $\mathrm{N}$ em cobertura $(45 ; 45$ e 75; 30, 60 e 90 dias após o transplante). De cada dose total de N, 25\% foram adicionados no plantio e o restante aplicado em uma ou dividido em duas ou três aplicações iguais. O transplante das mudas foi realizado na segunda quinzena de julho, e a colheita aproximadamente 120 dias depois. $\mathrm{O}$ rendimento de bulbos não foi influenciado pela adição de $\mathrm{N}$ na safra 2007/08, mas aumentou de forma quadrática com o aumento da quantidade de $\mathrm{N}$ aplicada nas safras 2008/09 e 2010/11, cujas doses estimadas do nutriente que proporcionaram a máxima eficiência econômica, foram respectivamente de $131 \mathrm{e} 102 \mathrm{~kg} \mathrm{ha}^{-1}$. Para a safra 2007/08 a dose mais econômica foi $0 \mathrm{~kg} \mathrm{ha}^{-1} \mathrm{de} \mathrm{N}$, já que não houve resposta à adubação com o nutriente. Na sequência das safras, os rendimentos máximos obtidos foram de 26, 42 e $43 \mathrm{t} \mathrm{ha}^{-1}$, cujos incrementos máximos proporcionados pelo $\mathrm{N}$, relativamente à ausência deste nutriente, foram de 0,32 e $9 \%$, respectivamente. A adição de $\mathrm{N}$ ao solo influenciou negativamente a conservação dos bulbos nos anos mais chuvosos. O aumento do número de aplicações de $\mathrm{N}$ em cobertura, de uma para duas ou três, não afetou o rendimento nem tampouco a conservação pós-colheita nas safras de 2007/08 e 2010/11, porém houve redução das perdas com maior parcelamento das doses intermediárias (50 e $100 \mathrm{~kg} \mathrm{ha}^{-1}$ ) de $\mathrm{N}$ na safra 2008/09.

Palavras-chave: Allium cepa, nitrogênio, nutrição, cultivo mínimo.

\begin{abstract}
Yield and conservation of onion affected by nitrogen fertilization in no-tillage system

Yield and conservation of onions are influenced by the nitrogen (N) availability in the soil. We evaluated the effect of rates and number of side dressing applications of nitrogen in the development, nutritional status of plants, yield and post-harvest storage of onion bulbs grown in no-tillage system. Three experiments were carried out in the field, over an Haplumbrept soil, in Ituporanga, Santa Catarina state, Brazil. Treatments consisted of a factorial combination (4x3) involving four rates of $\mathrm{N}\left(0,50,100\right.$ and $\left.200 \mathrm{~kg} \mathrm{ha}^{-1}\right)$ and three side dressing dates $(45 ; 45$ and $75 ; 30,60$ and 90 days after transplantation). For all $\mathrm{N}$ rates, $25 \%$ were applied at planting and the remaining amount was side dressed once or equally divided in two or three applications. The transplanting was carried out in the second half of July, and the harvest approximately 120 days later. Bulb yield was not influenced by $\mathrm{N}$ addition in the 2007/08 growing season, but it increased quadratically with increases on $\mathrm{N}$ applied in the other two seasons (2008/09 and 2010/11), and estimated $\mathrm{N}$ rates that provided the maximum economic efficiency was respectively 131 and $102 \mathrm{~kg} \mathrm{ha}^{-1}$. For the 2007/08 season, the most economic dose was $0 \mathrm{~kg} \mathrm{~N} \mathrm{ha}^{-1}$, since there was no response to fertilization with the nutrient. In the sequence of the seasons, maximum yields obtained were respectively 26,42 and $43 \mathrm{tha}^{-1}$, with increments of 0,32 and $9 \%$ relatively to the treatment without $\mathrm{N}$. The addition of nitrogen to the soil influenced negatively the conservation of the bulbs in the rainiest years. Two or three side dressing applications of $\mathrm{N}$ had no effect on yield and post harvest conservation of bulbs in 2007/08 and 2010/11, but losses were reduced with greater fragmentation of intermediate doses (50 and $100 \mathrm{~kg} \mathrm{ha}^{-1}$ ) of $\mathrm{N}$ in 2008/09.
\end{abstract}

Keywords: Allium cepa, nitrogen fertilization, nutrition, no tillage..

(Recebido para publicação em 26 de fevereiro de 2013; aceito em 9 de outubro de 2013) (Received on February 26, 2013; accepted on October 9, 2013)

\begin{abstract}
A cebola (Allium cepa) é a terceira hortaliça em importância econômica para o Brasil, sendo superada apenas pela batata e pelo tomate. Em 2012, foram cultivados 58 mil hectares de cebola no Brasil, cuja produção atingiu 1.357 mil toneladas, com rendi-
\end{abstract}

mento médio de 23,6 tha ${ }^{-1}$. A região Sul concentra mais de $50 \%$ desta produção, sendo Santa Catarina o principal estado produtor, com cerca de $30 \%$ da produção nacional nas últimas safras. Na safra 2012, o estado produziu 380 mil toneladas, com uma produtividade média de
$20 \mathrm{t} \mathrm{ha}^{-1}$ (IBGE, 2013).

$O$ rendimento de cebola, no entanto, é influenciado por vários fatores, como a disponibilidade de nutrientes, especialmente de nitrogênio. A disponibilidade de $\mathrm{N}$ no solo é afetada por diversas reações que podem reduzir a 
disponibilidade do elemento na solução do solo e, por conseguinte, impossibilitar sua absorção pelas plantas. Dentre estas, a lixiviação é a mais preocupante em regiões de alta precipitação pluviométrica, como o extremo sul do Brasil, especialmente em solos de textura arenosa. Devido à lixiviação, em algumas situações, recomenda-se aplicar os fertilizantes nitrogenados em duas ou mais vezes em cada ciclo vegetativo. O manejo adequado da adubação nitrogenada é necessário, uma vez que a eficiência de absorção deste nutriente pelas plantas varia de 15 a $30 \%$, sendo afetada pela dose, fonte, forma e época de aplicação, além de fatores climáticos e de vários atributos de solo (Wiedenfeld \& Braverman, 1991).

O nitrogênio é o segundo nutriente mais requerido pela cebola, sendo sua absorção superada apenas pelo potássio (K) (Pôrto et al., 2007), porém o N é dos que mais afeta o rendimento de bulbos (May, 2006; Resende \& Costa, 2009). A dose de $\mathrm{N}$ que proporciona a máxima produtividade depende da cultivar (May, 2006) e de atributos de solo, principalmente dos teores de argila e de matéria orgânica (Magalhães, 1988; Vidigal, 2000). As condições de cultivo também afetam a resposta da cebola ao nutriente (Batal et al., 1994). Dentre estas, destacam-se o manejo da adubação (parcelamento) e eventos meteorológicos, com ênfase à precipitação. As doses com maior eficiência técnica e econômica geralmente se situam entre 100 e $200 \mathrm{~kg} \mathrm{ha}^{-1}$ (Magalhães, 1988; Vidigal, 2000; May, 2006; Resende \& Costa, 2009; Kurtz et al., 2012).

Nos estados de Santa Catarina e Rio Grande do Sul, a recomendação de $\mathrm{N}$ considera os teores de matéria orgânica (MO) do solo. A dose máxima recomendada para cebola em solos com baixo teor de $\mathrm{MO}\left(<25 \mathrm{~g} \mathrm{~kg}^{-1}\right)$ é de $95 \mathrm{~kg}$ $\mathrm{ha}^{-1}$. Recomenda-se que as doses sejam parceladas em duas vezes, adicionando $50 \%$ por ocasião do transplante e o restante 45 dias após (CQFS-RS/SC, 2004). Kurtz et al. (2012) demonstraram que as doses recomendadas oficialmente são insuficientes para obter a máxima produtividade técnica e econômica no sistema de manejo convencional de solos que tenham teores baixos e mé- dios de argila e de MO. Estes autores estimaram as doses de maior retorno econômico para a cebola em $249 \mathrm{~kg}$ $\mathrm{ha}^{-1}$ de $\mathrm{N}$, em solo arenoso com baixo teor de $\mathrm{MO}$, e de 116 e $142 \mathrm{~kg} \mathrm{ha}^{-1}$ de $\mathrm{N}$, em solos com teores médios de argila e $\mathrm{MO}$, respectivamente nas safras 2006/07, 2008/09 e 2009/10. Diversos trabalhos realizados em outros estados brasileiros também indicaram a necessidade de doses maiores a $100 \mathrm{~kg} \mathrm{ha}^{-1}$ de $\mathrm{N}$ para obtenção de altos rendimentos (Magalhães, 1988; Vidigal, 2000; May, 2006; Resende et al., 2008; Resende \& Costa, 2009; Factor et al., 2009; Vidigal et al., 2010).

$\mathrm{O}$ parcelamento do $\mathrm{N}$ ao longo do ciclo da cultura constitui-se como uma prática cultural que pode aumentar a eficiência de uso do $\mathrm{N}$ aplicado. Maior número de aplicações em menores quantidades pode reduzir a lixiviação e a possibilidade de contaminação das águas subsuperficiais. Maiores doses aplicadas em um número maior de parcelamentos podem propiciar maiores produções de bulbos (Batal et al., 1994).

$\mathrm{O}$ sistema de plantio direto (SPD), baseado no revolvimento mínimo do solo, na rotação de culturas e na manutenção da cobertura com resíduos vegetais, apresenta vantagens no cultivo de cebola em relação ao manejo convencional do solo (Marouelli et al., 2008). A manutenção de maior cobertura do solo permite melhor proteção contra a erosão, a manutenção de maior quantidade de água no solo, a redução de plantas espontâneas e o favorecimento de aspectos químicos, físicos e biológicos do solo, devido ao maior aporte de matéria orgânica (Alvarenga et al., 1995). Portanto, a adição contínua de biomassa ao solo e a redução na intensidade de revolvimento são estratégias importantes para melhoria da condição estrutural, contribuindo para conservação do solo em áreas de produção hortícola, especialmente em ambientes sensíveis, como nas regiões declivosas (Pinheiro et al., 2004), comumente cultivadas com cebola e outras hortaliças em Santa Catarina. Convém ressaltar que o fornecimento de nutrientes pela biomassa das plantas se dá normalmente de maneira mais gradual em comparação aos adubos minerais solúveis. Isto em geral resulta em melhoria no aproveitamento do $\mathrm{N}$ proveniente dos resíduos, como também pela potencialização de outras modificações benéficas da cobertura vegetal em termos biológicos, químicos e físicos no solo (Aita et al., 2001). Estes fatores afetam a dinâmica do $\mathrm{N}$ e poderão alterar as respostas da cultura em relação ao sistema convencional de manejo do solo.

No presente trabalho objetivou-se avaliar o efeito de doses e do número de parcelamentos do $\mathrm{N}$ em cobertura no desenvolvimento das plantas, no rendimento e na conservação pós-colheita dos bulbos de cebola cultivada no sistema de manejo do solo com plantio direto.

\section{MATERIAL E MÉTODOS}

O presente trabalho foi constituído por três experimentos, conduzidos a campo, nas safras 2007/08, 2008/09 e 2010/11. Foram conduzidos na Estação Experimental da EPAGRI, no município de Ituporanga, região do Alto Vale do Itajaí, Santa Catarina ( $27^{\circ} 22^{\prime} \mathrm{S}, 49^{\circ} 35^{\prime} \mathrm{O}$, $475 \mathrm{~m}$ de altitude). Os experimentos foram instalados em Cambissolo Háplico Distrófico de textura média (Embrapa, 2006). Segundo a classificação de Köppen, o clima local é do tipo Cfa. Nas duas primeiras safras os experimentos foram conduzidos sobre a mesma área experimental; na terceira safra usou-se uma área anexa, distante 20 metros, porém com o mesmo manejo. Por ocasião da implantação dos experimentos, foram coletadas amostras de solo para determinação da composição química na camada de 0-20 cm. As análises apresentaram respectivamente, para as safras 2007/08, 2008/09 e 2010/11: $\mathrm{pH}-\mathrm{H}_{2} \mathrm{O}=6,6,6,5$ e 5,9; M.O. $\left(\mathrm{g} \mathrm{kg}^{-1}\right)=$ 35, 37 e 33; $\mathrm{P}\left(\mathrm{mg} \mathrm{kg}^{-1}\right)=22,31$ e 19; $\mathrm{K}\left(\mathrm{cmol}_{\mathrm{c}} \mathrm{kg}^{-1}\right)=0,57,0,82$ e 0,$31 ; \mathrm{Ca}$ $\left(\mathrm{cmol}_{\mathrm{c}} \mathrm{kg}^{-1}\right)=6,9,8,0$ e 7,$1 ; \mathrm{Mg}\left(\mathrm{cmol}_{\mathrm{c}}\right.$ $\left.\mathrm{kg}^{-1}\right)=3,1,3,5$ e 3,1 ; CTC $\left(\mathrm{cmol}_{\mathrm{c}} \mathrm{kg}^{-1}\right)=$ 12,8, 14,8 e 13,6; Argila $\left(\mathrm{g} \mathrm{kg}^{-1}\right)=260$, 330 e 320 . As áreas experimentais vêm sendo cultivadas desde 1995 com cebola em rotação de culturas no sistema de manejo do solo de plantio direto. Desde então, o solo não tem sido revolvido nem tampouco recebeu aplicação de calcário. Antes do plantio da cebola, na área experimental cultivou-se milheto 
(Pennisetum glaucum), o qual foi semeado em dezembro e acamado com rolo faca em maio do ano seguinte.

Durante a condução dos experimentos as precipitações pluviométricas (mm) mensais de julho a novembro e total do período segundo Epagri/Ciram, para as safras 2007/08, 2008/09 e 2010/11 foram respectivamente: julho= 234,37 e 88; agosto $=114,89$ e 98; setembro $=151$, 165 e 89 ; outubro $=217$, 386 e 181; novembro $=117,200$ e 86; total $=833,877$ e 542 .

Nos três experimentos, os tratamentos consistiram de um sistema fatorial (4x3) envolvendo quatro doses de $\mathrm{N}(0$, 50,100 e $200 \mathrm{~kg} \mathrm{ha}^{-1}$ ) e três parcelamentos da adubação nitrogenada de cobertura. Nos tratamentos que receberam N, $25 \%$ da quantidade total foi aplicado por ocasião do plantio das mudas, sendo o restante aplicado em uma, duas ou três vezes em cobertura. No tratamento com apenas um parcelamento (parcelamento 1), a adubação de cobertura foi realizada aos 45 dias após o transplante (DAT) das mudas; naqueles com dois ou três parcelamentos, as doses remanescentes de $\mathrm{N}$ foram igualmente divididas e aplicadas respectivamente aos $45 ; 45$ e 75; 30, 60 e 90 DAT. Usou-se nitrato de amônio como fonte de $\mathrm{N}$, aplicado a lanço sobre a superfície do solo, sem incorporação. $\mathrm{Na}$ adubação que antecedeu o plantio, também foram adicionados $90 \mathrm{~kg} \mathrm{ha}^{-1}$ de $\mathrm{K}_{2} \mathrm{O}$ distribuídos a lanço, na forma de $\mathrm{KCl}$ e $120 \mathrm{~kg} \mathrm{ha}^{-1}$ de $\mathrm{P}_{2} \mathrm{O}_{5}$, aplicados na linha de plantio, na forma de superfosfato triplo.

Utilizou-se o delineamento de blocos ao acaso, com quatro repetições. Cada unidade experimental tinha $3 \times 4 \mathrm{~m}$ e todas as avaliações foram feitas na área útil central de $6 \mathrm{~m}^{2}$. Avaliou-se a cultivar de cebola EMPASC 352-Bola Precoce e a produção de mudas foi realizada em canteiros. O transplante manual foi realizado na segunda quinzena de julho com mudas de $5 \mathrm{~mm}$ de diâmetro, obtidas 85 dias após a semeadura. A densidade foi de 10 plantas por metro linear, com espaçamento de $40 \mathrm{~cm}$ entre as linhas, totalizando 250.000 plantas por hectare. Os sulcos de plantio, com faixa de \pm 5 $\mathrm{cm}$, foram abertos pela passagem do equipamento "rotocaster" acoplado a um motocultivador.
O controle de plantas espontâneas, de pragas e de doenças foi realizado por meio de pulverizações com produtos químicos registrados no Ministério da Agricultura para a cultura da cebola. No controle de plantas espontâneas, foram efetuadas três aplicações com herbicidas e uma capina manual para retirada de plantas esporádicas não controladas pelos herbicidas. Para o controle de pragas, especialmente do tripes (Thrips tabaci), foram realizadas três aplicações com inseticidas. Para o controle de doenças fúngicas, principalmente de míldio (Peronospora destructor) e alternaria (Alternaria solani), foram realizadas cinco pulverizações com fungicidas.

$\mathrm{Na}$ primeira quinzena de outubro, por ocasião do inicio da bulbificação, foram coletadas amostras de folhas para avaliar o teor de nutrientes, amostrando a folha mais nova totalmente expandida de dez plantas por parcela. As folhas foram secas em estufa de ar forçado a $65^{\circ} \mathrm{C}$ até atingir massa constante, sendo a seguir moídas e submetidas à digestão sulfúrica. Nos extratos líquidos foram determinados os teores de $\mathrm{N}$, pelo método de arraste de vapores em aparelho semi-micro Kjeldahl (Tedesco et al., 1995). Nesta mesma época, nas safras 2008/09 e 2010/11, foi avaliado, em 10 plantas por parcela, o número de folhas, a altura e a arquitetura das plantas em função do número de folhas eretas, ou seja, de folhas que não estavam dobradas ou quebradas.

A colheita dos bulbos foi realizada, em média, 120 dias após o transplante, quando aproximadamente $70 \%$ das plantas apresentaram tombamento da parte aérea (estalamento). Após serem colhidos, os bulbos permaneceram na lavoura, sobre o solo, por 14 dias, no processo denominado de pré-cura. Posteriormente, os bulbos foram separados em sadios, deteriorados e florescidos, com posterior classificação comercial, pesagem e contagem. A classificação comercial foi feita pela medida do diâmetro, de acordo com a portaria 529 do Ministério da Agricultura (MAARA, 1995). Os bulbos com diâmetro maior do que $50 \mathrm{~mm}$ foram armazenados em galpão, dentro de caixas plásticas, por um período de 135 dias (4,5 meses) para avaliação da perda pós-colheita.
A produção de máxima eficiência econômica foi estimada pelo cálculo da derivada das equações de regressão obtidas entre a quantidade de $\mathrm{N}$ aplicada e a produtividade, considerando o preço médio do bulbo pago ao produtor ( $\mathrm{R} \$$ 0,59 $\mathrm{kg}^{-1}$ de bulbo) e do nitrogênio oriundo do nitrato de amônio ( $\mathrm{R} \$ 2,80$ $\mathrm{kg}^{-1}$ de N) nas últimas cinco safras (2007 a 2011).

$\mathrm{O}$ efeito dos fatores principais e da interação entre eles foram avaliados estatisticamente por meio da análise da variância; para o efeito das doses de $\mathrm{N}$, quando houve significância, foram ajustadas equações de regressão. Quando a análise de variância foi significativa para o fator parcelamento, as médias foram comparadas pelo teste de Tukey $(\mathrm{p} \leq 0,05)$.

\section{RESULTADOS E DISCUSSÃO}

Rendimento de bulbos - $\mathrm{O}$ efeito da adição de $\mathrm{N}$ ao solo no rendimento de bulbos de cebola variou com as safras (Figura 1a). Na safra 2007/08, a adição de $\mathrm{N}$ não afetou o rendimento de cebola, porém nas duas safras subsequentes (2008/09 e 2010/11), ele aumentou com a adição de $\mathrm{N}$ de forma quadrática. $\mathrm{Na}$ safra 2007/08, o rendimento médio foi de 25,8 $\mathrm{tha}^{-1}$. Nesta safra, o rendimento foi baixo em toda a região produtora catarinense, cujo rendimento médio foi de apenas 17,9 t ha $^{-1}$ (Schmitt \& Santos, 2009). O rendimento médio de cebola obtido nas três safras foi superior ao rendimento médio catarinense e brasileiro, que nos últimos anos situou-se próximo de $20 \mathrm{t} \mathrm{ha}^{-1}$.

A condução do estudo no sistema de plantio direto consolidado, também pode ter contribuído para a ausência de resposta à adição de $\mathrm{N}$, pois neste sistema pode ocorrer maior mineralização de $\mathrm{N}$ em alguns períodos, podendo atender à demanda da cultura (Sá, 1999). Outros autores também têm demonstrado não haver incremento no rendimento de cebola pela adição de $\mathrm{N}$ ao solo em algumas circunstâncias (Batal et al., 1994), e essas diferenças de resposta devem-se a fatores climáticos, à população de plantas e, principalmente, aos teores de MO do solo (Magalhães, 1988). Gonçalves 

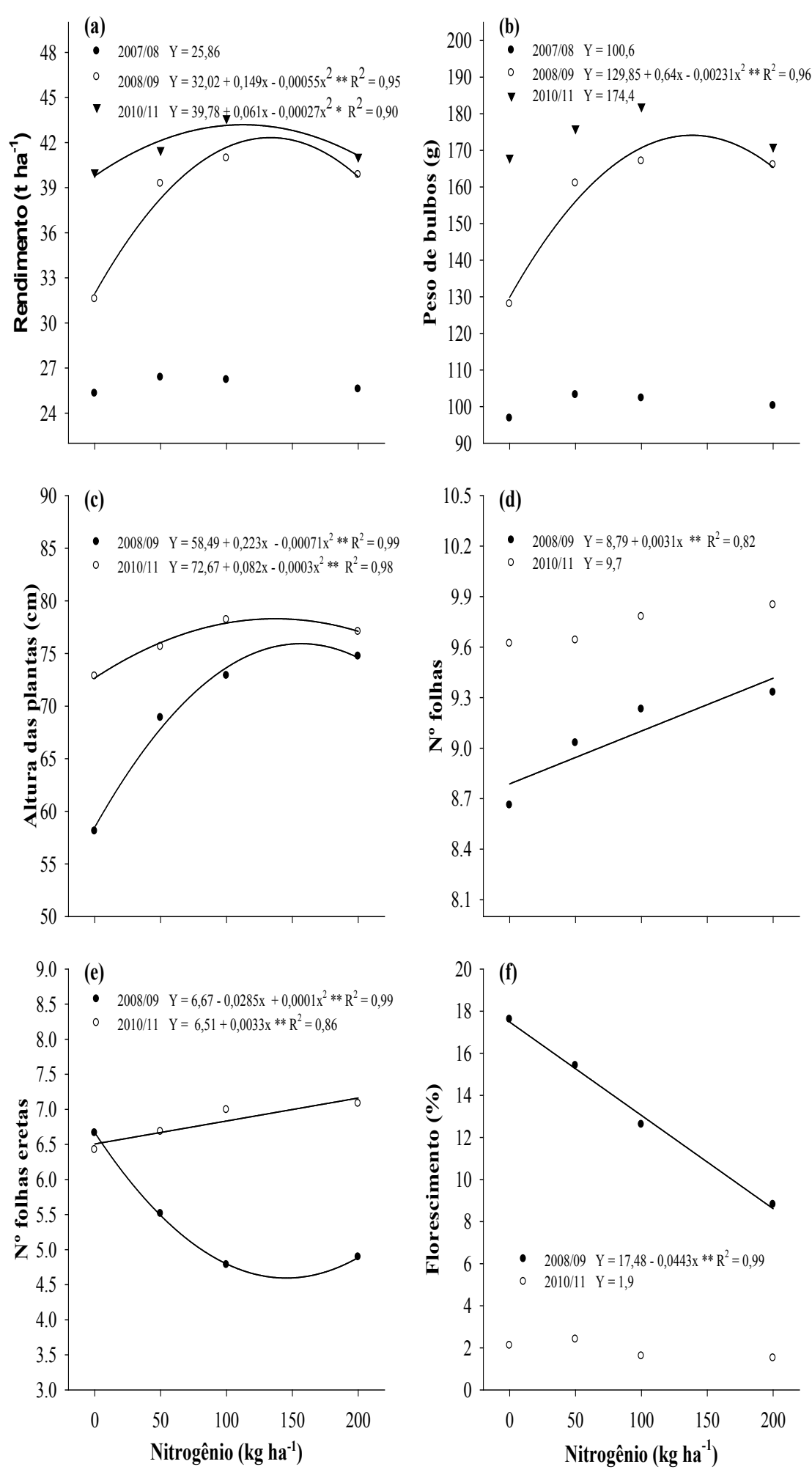

Figura 1. Rendimento (a), peso médio de bulbos (b) (três safras), altura de plantas (c), número de folhas (d), número de folhas eretas (e) e florescimento de cebola (f) (duas safras) em função da adição de doses crescentes de nitrogênio ao solo $(* p \leq 0,05 ; * * p \leq 0,01)$ [yield (a), average weight of bulbs (b) (three seasons), plant height (c), number of leaves (d), number of upright leaves (e) and flowering onions (f) (two seasons) depending on adding increasing levels of nitrogen to the soil $\left.\left({ }^{*} \mathrm{p} \leq 0.05,{ }^{*} \mathrm{p} \leq 0.01\right)\right]$. Ituporanga, Epagri, 2011. et al. (2009) também não observaram efeito da adição de doses de nitrogênio na produtividade da cebola cultivada no sistema plantio direto, em solo semelhante ao do presente estudo, com nível de matéria orgânica de $40 \mathrm{~g} \mathrm{~kg}^{-1}$. Estes autores utilizaram no entanto, uma cultivar de ciclo mais tardio, a Epagri 362 Crioula Alto Vale.

$\mathrm{Na}$ safra 2008/09, o rendimento aumentou de $32 \mathrm{t} \mathrm{ha}^{-1}$ na testemunha, que não recebeu adição de $\mathrm{N}$, para 42,1 t ha ${ }^{-1}$, na dose de máxima eficiência técnica (MET), obtida com a adição de $135 \mathrm{~kg} \mathrm{ha}^{-1}$ de $\mathrm{N}$, representando um incremento de $31,6 \%$. Na safra subsequente (2010/11), o rendimento aumentou de 39,8 para 43,2 $\mathrm{t} \mathrm{ha}^{-1}$, cujo incremento foi de apenas $8,6 \%$, obtido pela adição de $113 \mathrm{~kg} \mathrm{ha}^{-1}$ de N. Este menor incremento pode estar relacionado à menor lixiviação de nitrato, já que nos meses de maior desenvolvimento da cultura (setembro, outubro e novembro) choveu metade ou menos do que nos anos anteriores. Diversos pesquisadores têm constatado aumento no rendimento de cebola pela adição de $\mathrm{N}$ ao solo, em diversos locais e condições de cultivo, como observado nas safras 2008/09 e 2010/11 deste estudo. Kurtz et al. (2012) constataram, em experimentos conduzidos em sistema convencional de manejo do solo na região de Ituporanga-SC, que as doses de N para MET variaram de 265 $\mathrm{kg} \mathrm{ha}^{-1}$, em solo arenoso com baixo teor de $\mathrm{MO}$, a 124 e $153 \mathrm{~kg} \mathrm{ha}^{-1} \mathrm{em}$ solo com textura média e médio teor MO. Alguns estudos, também conduzidos em preparo convencional do solo, mostram que, para atingir $90 \%$ da produção máxima de bulbos comercializáveis, foram necessários entre 180 e $200 \mathrm{~kg} \mathrm{ha}^{-1} \mathrm{de} \mathrm{N}$, em solos com baixo teor de MO (6 e 14 $\mathrm{g} \mathrm{kg}^{-1}$ ) de Minas Gerais (Vidigal, 2000), e entre 105 e $125 \mathrm{~kg} \mathrm{ha}^{-1}$ de N, em um Latossolo argiloso (MO de $24 \mathrm{~g} \mathrm{~kg}^{-1}$ ) de São Paulo, dependendo da cultivar (May, 2006). Rodrigues (1992) constatou, em solo de Minas Gerais com MO de $40 \mathrm{~g} \mathrm{~kg}^{-1}$, que a dose de $120 \mathrm{~kg} \mathrm{ha}^{-1} \mathrm{de}$ $\mathrm{N}$ proporcionou a maior produção total e comercial de bulbos. Machado et al. (1984) aplicaram doses de $\mathrm{N}$ de 0 a 160 $\mathrm{kg} \mathrm{ha}^{-1}$ para três cultivares cultivadas em dois Cambissolos catarinenses, com 


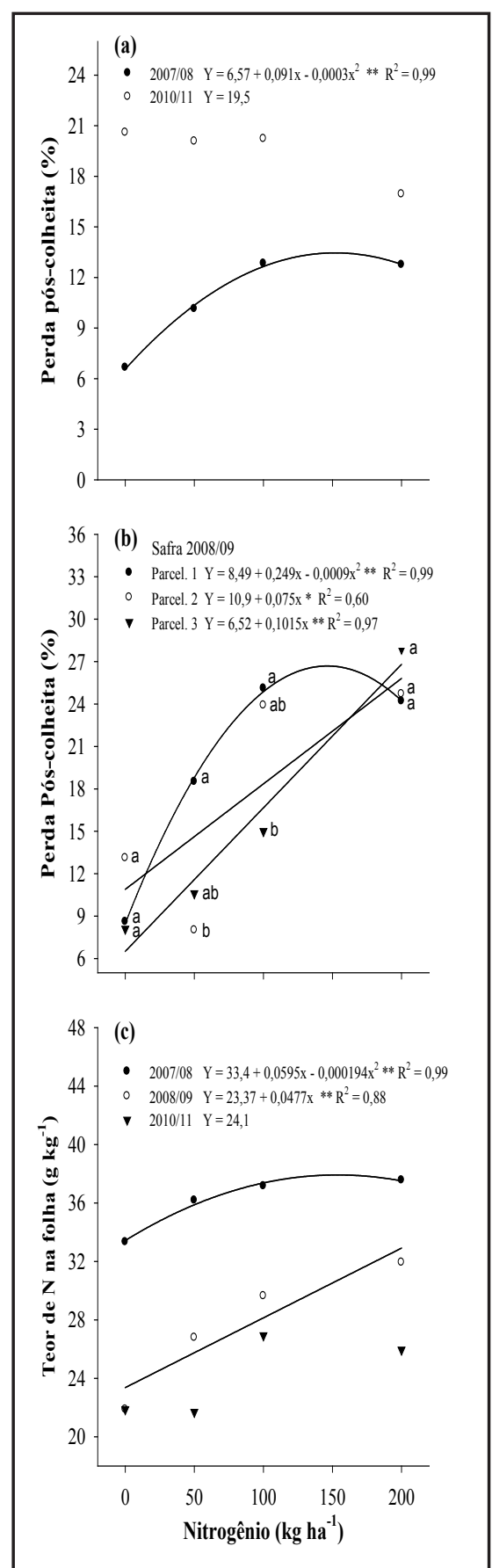

Figura 2. Perda pós-colheita de bulbos de cebola nas safras 2007/08 e 2010/11(a) e 2008/09 (b) e teor de N (c) em função da adição de doses crescentes de nitrogênio ao solo $\left({ }^{*} \mathrm{p} \leq 0,05 ;{ }^{*} \mathrm{p} \leq 0,01\right)$; letras iguais dentro de cada dose não diferem pelo teste de Tukey $(p \leq 0,05)$ para perda em pós-colheita para o fator parcelamento (safra 2008/09) [postharvest loss of onion bulb in 2007/08 and 2010/11 (a) and 2008/09 (b) and N content (c) depending on adding increasing doses of nitrogen to the soil $\left({ }^{*} \mathrm{p} \leq 0.05\right.$; $* * \mathrm{p} \leq 0.01)$; same letters within each dose did not differ by Tukey test $(\mathrm{p} \leq 0.05))$ to postharvest losses for installment factors (harvest 2008/09)]. Ituporanga, Epagri, 2011.
35 e $51 \mathrm{~g} \mathrm{~kg}^{-1}$ de $\mathrm{MO}$ respectivamente. Estes autores verificaram que a resposta da cebola ao $\mathrm{N}$ foi inconstante, porém pequenos incrementos ocorreram para doses acima de $40 \mathrm{~kg} \mathrm{ha}^{-1}$. A dose que proporcionou o máximo rendimento foi de $65 \mathrm{~kg} \mathrm{ha}^{-1}$ de $\mathrm{N}$.

O cálculo do retorno econômico da produção de cebola em função da adubação nitrogenada demonstrou que a máxima eficiência econômica seria atingida com a aplicação de 131 e 102 $\mathrm{kg} \mathrm{ha}^{-1}$ de N, respectivamente nas safras 2008/09 e 2010/11. Para a safra 2007/08 a dose mais econômica seria $0 \mathrm{~kg} \mathrm{ha}^{-1} \mathrm{de}$ $\mathrm{N}$, já que não houve resposta à adubação com o nutriente. Portanto, verifica-se que as doses recomendadas atualmente para os estados do RS e SC (CQFS-RS/ SC, 2004), são insuficientes para atingir a máxima eficiência econômica para a cultura da cebola. Resultados semelhantes foram obtidos por outros pesquisadores para regiões de São Paulo (May, 2006; Factor et al., 2009), Minas Gerais (Vidigal, 2000; Vidigal et al., 2010), Nordeste (Resende et al., 2008; Resende $\&$ Costa, 2009) e Santa Catarina (Kurtz et al., 2012).

O peso médio de bulbos aumentou pela adição de $\mathrm{N}$ somente na safra 2008/09 (Figura 1b). Nesta safra, o aumento no peso teve comportamento quadrático, passando de $130 \mathrm{~g}$ na testemunha para $174 \mathrm{~g}$ no ponto de MET, cujo incremento de $34 \%$, seria obtido com a adição de $138 \mathrm{~kg} \mathrm{ha}^{-1}$ de N. Para as safras 2007/08 e 2010/11, o valor médio do peso de bulbos foi de 101 e 174 g, respectivamente. Kurtz et al. (2012) verificaram que as doses que proporcionaram os maiores pesos de bulbos foram de 283, 112 e $156 \mathrm{~kg}$ $\mathrm{ha}^{-1}$ de $\mathrm{N}$, respectivamente para solo de textura arenosa e médias, conduzidos em sistema convencional de manejo do solo. Resende et al. (2008), em trabalho realizado em solo do Nordeste brasileiro, verificaram que a dose de $114 \mathrm{~kg} \mathrm{ha}^{-1}$ de $\mathrm{N}$ proporcionou maior peso de bulbos. Aumentos no peso de bulbos com o aumento na adição de $\mathrm{N}$ foram também obtidos por Machado et al. (1984), Batal et al. (1994) e May (2006).

A quantidade de bulbos com diâmetro inferior a $50 \mathrm{~mm}$ não foi afetada pelos tratamentos e foram de $12,0 \%$,
$1,0 \%$ e $2,5 \%$, respectivamente nas safras 2007/08, 2008/09 e 2010/11. A obtenção de bulbos maiores, além de estar diretamente relacionada com o aumento no rendimento, também aumenta a lucratividade dos produtores, pois bulbos com diâmetro inferior a $50 \mathrm{~mm}$ apresentam menor valor de mercado. Os bulbos de peso médio, ao redor de $150 \mathrm{~g}$ são os preferidos comercialmente. Bulbos de tamanho muito grande devem ser evitados pois, além de terem menor aceitação comercial, são mais suscetíveis ao apodrecimento (Batal et al., 1994).

Morfologia das plantas (altura, $\mathrm{n}^{\circ}$ de folhas, $n^{\circ}$ folhas eretas e florescimento) - $\mathrm{O}$ incremento da quantidade de $\mathrm{N}$ adicionada aumentou de forma quadrática à altura de plantas nas duas safras avaliadas (Figura 1c). As alturas máximas foram de 76 e $78 \mathrm{~cm}$ para doses de 137 e $143 \mathrm{~kg} \mathrm{ha}^{-1}$ de $\mathrm{N}$, respectivamente nas safras 2008/09 e 2010/11. May (2006) também obteve incrementos na altura de plantas com a aplicação de $\mathrm{N}$, atingindo $80 \mathrm{~cm}$ pela adição de 150 $\mathrm{kg} \mathrm{ha}^{-1}$ de N. Os resultados mostram que, para atingir a altura máxima das plantas, são necessárias quantidades maiores de $\mathrm{N}$ do que aquelas para obter $\mathrm{o}$ rendimento máximo, concordando com Kurtz et al. (2012) e demonstrando que não são as maiores alturas ou portes de planta que irão proporcionar os maiores rendimentos de bulbos.

O número de folhas por planta aumentou com o incremento nas doses de N na safra 2008/09, mas não sofreu alteração na safra seguinte (Figura 1d). Na safra 2008/09, o aumento foi linear, passando de 8,8 folhas por planta, na testemunha, para 9,4 no tratamento com a maior dose aplicada (200 $\left.\mathrm{kg} \mathrm{ha}^{-1} \mathrm{de} \mathrm{N}\right)$. Na safra 2010/11, o número de folhas foi em média de 9,7 por planta, situando-se acima da safra anterior, o que justifica em parte, o maior rendimento obtido nesta safra. $\mathrm{O}$ incremento no número de folhas por planta de cebola pela adição de $\mathrm{N}$ foram também obtidos por May (2006) e Kurtz et al. (2012). A quantidade de folhas e respectiva área foliar por planta estão diretamente relacionadas com o rendimento, que pode ser explicado pela maior área fotossintética e, principalmente, pelo fato de o bulbo ser formado pelo acúmulo de reservas 
Tabela 1. Rendimento, peso médio de bulbos, teor de $\mathrm{N}$ das folhas, altura de planta, $\mathrm{n}^{\circ}$ de folhas, $\mathrm{n}^{\circ}$ de folhas eretas, florescimento e perda pós-colheita em função do parcelamento de doses de nitrogênio na cultura da cebola em três safras (média dos valores observados com as doses de 0,50, 100 e $200 \mathrm{~kg} \mathrm{ha}^{-1}$ ) [yield, average bulb weight, $\mathrm{N}$ content of the leaves, plant height, number of leaves and upright leaves, flowering and post-harvest losses due to splitting of nitrogen on onion crops in three seasons (average values observed with doses of 0, 50, 100 and $\left.200 \mathrm{~kg} \mathrm{ha}^{-1}\right)$ ]. Ituporanga, Epagri, 2011.

\begin{tabular}{|c|c|c|c|}
\hline \multirow{2}{*}{ Variáveis } & \multicolumn{3}{|c|}{ Parcelamento } \\
\hline & $1 *$ & 2 & 3 \\
\hline & \multicolumn{3}{|c|}{ Safra $2007 / 08$} \\
\hline Rendimento ( $\left.\mathrm{t} \mathrm{ha}^{-1}\right)$ & 25,78 n.s. & 25,79 & 25,99 \\
\hline Peso médio bulbos (g) & 101,00 n.s. & 100,00 & 101,00 \\
\hline \multirow[t]{2}{*}{$\mathrm{N}$ foliar $\left(\mathrm{g} \mathrm{kg}^{-1}\right)$} & 36,80 n.s. & 37,50 & 35,60 \\
\hline & \multicolumn{3}{|c|}{ Safra 2008/09 } \\
\hline Rendimento ( $\left.\mathrm{t} \mathrm{ha}^{-1}\right)$ & $38,38 \mathrm{~ns}$ & 37,08 & 38,36 \\
\hline Peso médio bulbos (g) & $156,00 \mathrm{~ns}$ & 155,00 & 155,00 \\
\hline $\mathrm{N}$ foliar $\left(\mathrm{g} \mathrm{kg}^{-1}\right)$ & $29,90 \mathrm{~A}$ & $27,50 \mathrm{AB}$ & $25,30 \mathrm{~B}$ \\
\hline Altura de planta $(\mathrm{cm})$ & $70,70 \mathrm{~A}$ & $68,60 \mathrm{AB}$ & $66,60 \mathrm{~B}$ \\
\hline $\mathrm{N}^{\mathrm{o}}$ de folhas & $9,20 \mathrm{~ns}$ & 9,10 & 9,00 \\
\hline $\mathrm{N}^{\mathrm{o}}$ folhas eretas & $5,20 \mathrm{~B}$ & $5,30 \mathrm{~B}$ & $5,90 \mathrm{~A}$ \\
\hline Florescimento (\%) & $11,40 \mathrm{~B}$ & $13,60 \mathrm{AB}$ & $15,80 \mathrm{~A}$ \\
\hline \multirow[t]{2}{*}{ Perda pós-colheita (\%) } & $19,10 \mathrm{~ns}$ & 17,40 & 15,40 \\
\hline & \multicolumn{3}{|c|}{ Safra 2010/11 } \\
\hline Rendimento ( $\left.\mathrm{t} \mathrm{ha}^{-1}\right)$ & $41,77 \mathrm{~ns}$ & 41,32 & 41,55 \\
\hline Peso médio bulbos (g) & $173,00 \mathrm{~ns}$ & 175,00 & 175,00 \\
\hline $\mathrm{N}$ foliar $\left(\mathrm{g} \mathrm{kg}^{-1}\right)$ & $24,60 \mathrm{~ns}$ & 24,80 & 23,00 \\
\hline Altura de planta $(\mathrm{cm})$ & $75,60 \mathrm{~ns}$ & 75,50 & 76,70 \\
\hline $\mathrm{N}^{\mathrm{o}}$ de folhas & $9,70 \mathrm{~ns}$ & 9,60 & 9,80 \\
\hline $\mathrm{N}^{\mathrm{o}}$ folhas eretas & $6,70 \mathrm{~ns}$ & 6,60 & 7,00 \\
\hline Florescimento (\%) & $1,60 \mathrm{AB}$ & $3,00 \mathrm{~A}$ & $1,10 \mathrm{~B}$ \\
\hline Perda pós-colheita (\%) & $21,40 \mathrm{~ns}$ & 19,60 & 17,40 \\
\hline
\end{tabular}

*Parcelamento $1=25 \%$ da dose de $\mathrm{N}$ no transplante e $75 \%$ aos 45 dias após o transplante (DAT); Parcelamento $2=25 \%$ da dose no transplante, $37,5 \%$ aos 45 DAT e $37,5 \%$ aos 75 DAT; Parcelamento $3=25 \%$ da dose em cada uma das seguintes épocas: transplante, $30,60 \mathrm{e}$ 90 DAT. Médias seguidas de mesma letra, na linha, não diferem entre si pelo teste de Tukey a $5 \%$ de significância. ns = não significativo [ $*$ parceling $1=25 \%$ of $\mathrm{N}$ in the transplant and $75 \%$ at 45 days after transplanting (DAT); Parceling $2=25 \%$ of the dose in transplant, $37.5 \%$ at 45 DAT and $37.5 \%$ at 75 DAT; Parceling $3=25 \%$ of the dose in each of the following times: transplant, 30, 60 and 90 DAT. Means followed by the same letter in the line do not differ by Tukey test at $5 \%$ significance. $n s=$ not significant].

na base da bainha de cada folha correspondente (Brewster, 2008; INIA, 2005).

A arquitetura das plantas, avaliada pelo número de folhas eretas comportou-se de maneira diferente nas duas safras avaliadas (Figura 1e). Na safra 2008/09 ocorreu uma diminuição de forma quadrática do número de folhas eretas com o aumento das doses de $\mathrm{N}$, enquanto que na safra 2010/11, ocorreu o contrário, ou seja, aumentou linear- mente com o incremento da dose de $\mathrm{N}$. $\mathrm{Na}$ safra 2008/09, o número de folhas eretas diminuiu de 6,7 na testemunha para um mínimo de 4,6 na dose de 143 $\mathrm{kg} \mathrm{ha}^{-1}$ de N. Na safra 2010/11, o número de folhas eretas aumentou de 6,5 , sem adição de $\mathrm{N}$, para 7,2 na dose de 200 $\mathrm{kg} \mathrm{ha}^{-1}$. Os resultados contrastantes nas duas safras podem ser explicados, em parte, pelo excesso de chuvas em outubro de 2008, superando em mais de
$100 \%$ a precipitação ocorrida no mesmo mês de 2010. Isso também contribuiu para menor tempo de radiação solar, formando plantas mais estioladas e suscetíveis a dobra e quebra das folhas. Outro fator que pode ter contribuído é o teor de cálcio $(\mathrm{Ca})$ que foi em média de $7,3 \mathrm{~g} \mathrm{~kg}^{-1}$ na safra $2008 / 09$ e de $10 \mathrm{~g} \mathrm{~kg}^{-1}$ na safra 2010/11 (dados não apresentados). O Ca é um elemento estrutural, pois o pectato de Ca na lamela média da parede celular atua como agente cimentante entre as células (Malavolta, 2006), concedendo maior firmeza às folhas. $\mathrm{O}$ ideal seria que as plantas tivessem o maior número possível de folhas eretas, para facilitar e aumentar a interceptação da luz solar e permitir melhor eficiência das pulverizações fitossanitárias.

A quantidade de plantas florescidas diminuiu na safra 2008/09 com o aumento da dose de $\mathrm{N}$, mas não foi influenciada nas demais safras (Figura 1f). Na safra $2008 / 09,17,5 \%$ das plantas floresceram no tratamento sem a adição de $\mathrm{N}$, enquanto que somente $8,6 \%$ floresceram no tratamento com $200 \mathrm{~kg} \mathrm{ha}^{-1}$ de N. Considerando que os bulbos de plantas florescidas não apresentam valor comercial, as perdas nesta safra foram expressivas, porém foram amenizadas nos tratamentos que receberam mais $\mathrm{N}$. $\mathrm{Na}$ dose de MET (135 kg ha-1 de N) a perda estimada foi de $11,5 \%$, representando uma redução de $6 \%$, em relação à testemunha. A redução no florescimento ocorreu provavelmente porque $\mathrm{o} \mathrm{N}$ pode retardar ou até inibir o florescimento de algumas espécies de plantas (Vaz et al., 2004). O florescimento das plantas é influenciado também pelas condições climáticas, principalmente pela ocorrência de temperaturas excessivamente baixas (Barbosa, 2008). Na safra 2007/08, não ocorreu florescimento das plantas e na safra 2010/11 a quantidade de plantas florescidas foi baixa (2\%).

Perda de bulbos em pós-colheita Na safra 2008/09, houve interação entre doses e parcelamentos de $\mathrm{N}$ no tocante às perdas de bulbos armazenados por 4,5 meses, diferentemente das demais safras (Figura 2a e 2b). Nas safras 2007/08, as perdas aumentaram com o incremento das doses de $\mathrm{N}$ passando de $6,6 \%$ na testemunha para um máximo de $12,5 \%$, obtida com a adição de $152 \mathrm{~kg} \mathrm{ha}^{-1}$ de 
N; na safra 2010/11, as perdas no armazenamento não foram influenciadas pela aplicação de $\mathrm{N}$ e situaram-se, na média, em 19,5\% (Figura 2a).

Para a safra 2008/09, em que ocorreu interação entre doses e parcelamentos, observou-se aumento das perdas com o incremento da dose de $\mathrm{N}$ para todos os parcelamentos, embora com comportamento diferente entre estes (Figura 2b). No tratamento com somente um parcelamento do $\mathrm{N}$ as perdas tiveram comportamento quadrático, passando de $8,5 \%$ na testemunha para um máximo de $25,7 \%$ na dose de $138 \mathrm{~kg} \mathrm{ha}^{-1}$ de N. Entretanto, para os parcelamentos 2 e 3 as perdas em pós-colheita tiveram incremento de forma linear. Este comportamento diferenciado para o tratamento parcelamento 1 , pode ter ocorrido em função de todo o $\mathrm{N}$ da adubação de cobertura ter sido adicionado em uma única aplicação, na fase inicial, aos 45 DAT, de forma que mesmo nos tratamentos com doses menores $(50 \mathrm{e}$ $100 \mathrm{~kg} \mathrm{ha}^{-1}$ ), ocorressem perdas maiores e semelhantes à maior dose $(200$ $\mathrm{kg} \mathrm{ha} \mathrm{h}^{-1}$ ). Possivelmente, isso ocorreu, pela saturação dos sítios de absorção das plantas quando o $\mathrm{N}$ foi aplicado em uma única vez, mesmo nas menores doses. Este comportamento fica mais claramente demonstrado quando foram desmembrados os parcelamentos dentro de cada dose (Figura 2b), onde as doses de 50 e $100 \mathrm{~kg} \mathrm{ha}^{-1}$ tiveram menores perdas quando a adubação nitrogenada foi adicionada em mais de uma aplicação, conforme observou-se no teste de comparação de médias dos parcelamentos dentro de cada dose (Tukey $\leq 0,05$ ). Neste caso, para a dose de $50 \mathrm{~kg} \mathrm{ha}^{-1} \mathrm{o}$ parcelamento em duas vezes apresentou as menores perdas, enquanto que, para a dose de $100 \mathrm{~kg} \mathrm{ha}^{-1}$ as menores perdas ocorreram para o parcelamento do $\mathrm{N}$ em cobertura em três vezes. Já para a dose de $200 \mathrm{~kg} \mathrm{ha}^{-1}$ não se observou efeito dos parcelamentos, provavelmente por exceder as necessidades das plantas, mesmo quando aplicada de maneira mais parcelada ao longo do ciclo.

As diferenças entre a safra 2010/11, não afetada pela aplicação de $\mathrm{N}$, e as outras duas safras que apresentaram perdas em pós-colheita pela adição de $\mathrm{N}$, provavelmente se devem às condi- ções climáticas associadas ao teor de $\mathrm{N}$ nas plantas, sobretudo ao excesso de chuvas ocorridas, principalmente, no mês de outubro das safras 2007/08 e 2008/09. O excesso de chuvas, aliado a altas temperaturas, favorece a incidência de doenças bacterianas, que são as principais responsáveis pelo apodrecimento dos bulbos durante o armazenamento (Wordell Filho \& Boff, 2006). Estes autores sugerem o uso de doses mínimas necessárias de $\mathrm{N}$ como medida para evitar perdas pós-colheita por bacteriose em cebola. Por isso, em anos com previsão de alta pluviosidade no final do ciclo, como ocorreu na safra 2008/09 (Tabela 2), é prudente adicionar doses menores de $\mathrm{N}$ quando se pretende armazenar os bulbos. Nesta safra, o rendimento de MET calculado após 4,5 meses de armazenamento, seria obtido com a dose de $39 \mathrm{~kg} \mathrm{ha}^{-1}$ de $\mathrm{N}$ (dados não apresentados), bem inferior aos $135 \mathrm{~kg} \mathrm{ha}^{-1}$, necessários para a MET por ocasião da colheita. Isso evidencia que, quando se pretende armazenar a produção de bulbos em anos chuvosos, as doses devem ser menores. Na safra 2010/2011, quando não houve excesso de chuvas (Tabela 2), a adição de $\mathrm{N}$ não alterou negativamente a armazenagem dos bulbos. Aumentos na perda pós-colheita com o incremento das doses de N também foram obtidos por Singh \& Dhankhar (1991) e Kurtz et al. (2012), em anos mais chuvosos. Dessa forma, fica evidente que aumentos nas perdas pós-colheita pelo incremento nas doses de $\mathrm{N}$, têm ocorrido quando há excesso de chuvas. No entanto, Hussaini et al. (2000) não observaram efeitos da adição de $\mathrm{N}$ na conservação de bulbos pela adição de até $164 \mathrm{~kg} \mathrm{ha-1}$.

Teores de $\mathbf{N}$ na planta - $\mathrm{O}$ aumento das doses de $\mathrm{N}$ aplicadas ao solo aumentou os teores de $\mathrm{N}$ nas folhas de cebola, de forma quadrática na safra 2007/08 e de forma linear na safra 2008/09, porém não exerceu influência na safra 2010/11 (Figura 2c). Na safra 2007/08, a concentração foi de $33 \mathrm{~g} \mathrm{~kg}^{-1}$ na testemunha e atingiu um máximo de $38 \mathrm{~g} \mathrm{~kg}^{-1}$, com a adição de $153 \mathrm{~kg} \mathrm{ha}^{-1}$ de N. Embora o incremento no teor de $\mathrm{N}$ nesta safra seja expressivo, este não influenciou o rendimento, indicando que naquele ano o fator limitante para esta variável não se deve ao $\mathrm{N}$, conforme já discutido. Por outro lado, o incremento das doses de $\mathrm{N}$ influenciou negativamente a conservação dos bulbos, de modo que a adição de $152 \mathrm{~kg} \mathrm{ha}^{-1}$ de $\mathrm{N}$, dose que coincide com maior teor de $\mathrm{N}$ no tecido foliar (153 $\left.\mathrm{kg} \mathrm{ha}^{-1}\right)$, foi a que ocasionou maiores perdas de bulbos em pós-colheita. Na safra seguinte, os teores de $\mathrm{N}$ variam de $23 \mathrm{~g} \mathrm{~kg}^{-1}$ na testemunha para $33 \mathrm{~g} \mathrm{~kg}^{-1}$ na maior dose avaliada. Considerando a dose de MET para esta safra (135 kg ha-1 de N) o teor de $\mathrm{N}$ estimado pela equação (Figura 2c) para obter o rendimento máximo foi de $30 \mathrm{~g}$ $\mathrm{kg}^{-1}$. Na safra 2010/11, quando os teores não foram afetados pelas doses de $\mathrm{N}$, os valores situaram-se em média de $24 \mathrm{~g}$ $\mathrm{kg}^{-1}$. Nesta safra, embora os teores de $\mathrm{N}$ no tecido foliar não forem afetados pelo incremento das doses de $\mathrm{N}$, as plantas responderam ao elemento pelo maior rendimento de bulbos observado. Nesta safra, as chuvas foram bem abaixo dos valores registrados nas safras anteriores, podendo ser um fator limitante à absorção deste elemento. Para as três safras os teores obtidos situaram-se na faixa adequada de $\mathrm{N}$ para a cebola que estão entre 19 e $40 \mathrm{~g} \mathrm{~kg}^{-1}$ (Jones Júnior et al., 1991; Caldwell et al., 1994).

Parcelamento da adubação nitrogenada - Como não houve interação entre doses de $\mathrm{N}$ e o parcelamento da adubação de cobertura para as variáveis avaliadas nas três safras, os dados apresentados na Tabela 1 representam as médias das doses dentro de cada parcelamento. A única exceção ocorreu para as perdas em pós-colheita, na safra 2008/09, conforme discutido anteriormente.

O rendimento de bulbos não foi afetado em nenhuma das safras avaliadas pelo parcelamento das doses de $\mathrm{N}$ e as médias situaram-se em 25,8, 37,8 e 41,5 $\mathrm{t} \mathrm{ha-1}$, respectivamente para as safras 2007/08, 2009/10 e 2010/11. Sá et al. (2004) e Kurtz et al. (2012) também verificaram que o parcelamento do $\mathrm{N}$ não alterou o rendimento e a conservação dos bulbos. Ao contrário dos resultados obtidos neste estudo, alguns autores observaram que altas doses aplicadas em maior número de vezes proporcionaram maiores produções de cebola (Batal et al., 1994; Vidigal, 
2000; Factor, et al., 2009). Machado et al. (1984), trabalhando com dois Cambissolos da região de Ituporanga-SC, verificaram que o melhor rendimento foi obtido com a adubação nitrogenada dividida em três parcelas, sendo um terço no plantio, um terço aos 30 DAT e um terço aos 60 DAT.

$\mathrm{O}$ teor de $\mathrm{N}$ foliar não foi afetado pelo parcelamento nas safras 2007/08 e 2010/11, situando-se em 36,6 e 24,1 $\mathrm{g} \mathrm{kg}^{-1}$, respectivamente. Já na safra 2008/09, o parcelamento do $\mathrm{N}$ em maior número, reduziu os teores foliares de $\mathrm{N}$, passando de 29,9 $\mathrm{g} \mathrm{kg}^{-1}$ com uma aplicação para $25,3 \mathrm{~g} \mathrm{~kg}^{-1}$ quando se parcelou o $\mathrm{N}$ em três aplicações. Esta redução pode ter ocorrido em função da amostragem de folhas ter sido realizada antes da última aplicação de $\mathrm{N}$ no parcelamento 3. A altura de plantas reduziu com o maior parcelamento da adubação de cobertura na safra 2008/09 passando de $70,7 \mathrm{~cm}$ com aplicação única para $66,6 \mathrm{~cm}$ no parcelamento 3 . No entanto, esta variável não foi afetada na safra 2010/11 situando-se em 75,9 cm em média. A quantidade de folhas eretas e o florescimento aumentaram com maior número de parcelamentos do $\mathrm{N}$ em cobertura, ambos na safra 2008/09. O florescimento prematuro aumentou com o maior parcelamento do $\mathrm{N}$ na safra 2008/09, enquanto que na safra 2010/11 o florescimento foi menor quando o parcelamento foi realizado em três vezes.

Os resultados obtidos permitem concluir que o rendimento de cebola aumentou com a aplicação $\mathrm{N}$ em duas das três safras avaliadas e as doses que proporcionaram o máximo retorno econômico foram de 131 e $102 \mathrm{~kg} \mathrm{ha}^{-1}$, respectivamente nas safras 2008/09 e 2010/11. Para a safra 2007/08, a dose mais econômica foi de $0 \mathrm{~kg} \mathrm{ha}^{-1}$ de $\mathrm{N}$, já que não houve resposta à adubação com o nutriente. $\mathrm{O}$ parcelamento da adubação nitrogenada não afetou o rendimento nem a conservação pós-colheita nas safras de 2007/08 e 2010/11, porém houve redução das perdas com o maior parcelamento nas doses de 50 e $100 \mathrm{~kg}$ ha $^{-1}$ de $\mathrm{N}$ na safra 2008/09. As perdas de bulbos em pós-colheita aumentam com a adição de $\mathrm{N}$, especialmente nos anos mais chuvosos.

\section{AGRADECIMENTOS}

Os autores agradecem à FAPESC pelo auxílio financeiro para realização das pesquisas (PROCESSO 15047/20119, SDR) e aos colaboradores técnico agrícola Marcelo Pitz e assistente de campo Olindo André, da Epagri, Estação Experimental de Ituporanga-SC.

\section{REFERÊNCIAS}

AITA C; BASSO CJ; CERETTA CA; GONÇALVES CN; ROS CO. 2001. Plantas de cobertura do solo como fonte de nitrogênio ao milho. Revista Brasileira Ciência do Solo 25: 157-165.

ALVARENGA RC; COSTALM; MOURAFILHO W; REGAZZI AJ. 1995. Características de adubos verdes de interesse para a conservação e recuperação de solos. Pesquisa Agropecuária Brasileira 20: 175-185.

BARBOSA CA. 2008. Manual da cultura da cebola. Viçosa. 149p.

BATAL KM; BONDARI K; GRANBERRY DM; MULLINIX BG. 1994. Effects of source, rate, and frequency of $\mathrm{N}$ application on yield, marketable and rot incidence of sweet onion (Allium cepa L. cv. granex-33). Journal Horticultural Science 69: 1043-1051.

BREWSTER JL. 2008. Onions and other vegetable alliums. 2 ed. Wellesbourne, UK. $455 \mathrm{p}$.

CALDWELL JON; SUMNER ME; VAVRINA CS. 1994. Development and testing of preliminary foliar DRIS norms for onions. HortScience 29: 1501-1504.

COMISSÃO DE QUÍMICA E FERTILIDADE DO SOLO - CQFS-RS/SC. 2004. Manual de adubação e calagem para os Estados do Rio Grande do Sul e de Santa Catarina. 10. ed. Porto Alegre: Sociedade Brasileira de Ciência do Solo/Núcleo Regional Sul/UFRGS. 394p.

EMBRAPA 2006. Sistema brasileiro de classificação de solos. 2. Ed. Rio de Janeiro: Embrapa Solos. 306p.

FACTOR TL; LIMA JUNIOR S; PURQUERIO LFV; TIVELLI SW; TRANI PE; BREDA JUNIOR JM; ROCHA MAV. 2009. Manejo da adubação nitrogenada na produção de cebola em plantio direto. In: CONGRESSO BRASILEIRO DE OLERICULTURA 49. Horticultura Brasileira 27: Suplemento CD-ROM.

GONÇALVES PAS; WORDELL FILHO JA; KURTZ C. 2009. Efeitos da adubação sobre a incidência de tripes e míldio e na produtivdade da cultura da cebola. Agropecuária Catarinense 22: 57-60.

HUSSAINI MA; AMANS EB; RAMALAN AA. 2000. Yield, bulb size distribution and storability of onion (Allium cepa L.) under different levels of $\mathrm{N}$ fertilization and irrigation regime. Tropical Agriculture 77: 145-149.

IBGE - Instituto Brasileiro de Geografia e Estatística. 2013. 15 de fevereiro. Sistema
IBGE de recuperação automática - SIDRA. Disponível em www.sidra.ibge.gov.br

INIA - Instituto Nacional de Investigacion Agropecuária do Uruguai. 2005. Tecnología para la producción de cebolla. Montevideo: Unidad de Agronegocios y Difusión Del INIA. 247p. (Boletin de Divulgacion 88).

JONES JUNIOR JB; WOLF B; MILLS HA. 1991. Plant analysis and analysis handbook: a practical sampling, preparation, analysis and interpretation guide. Athen: MicroMacro. 213p.

KURTZ C; ERNANI PR; COIMBRA JLM; PETRY E. 2012. Rendimento e conservação de cebola alterados pela dose e parcelamento de nitrogênio em cobertura. Revista Brasileira de Ciência do Solo 36: 865-876.

MACHADO MO; VIZZOTTOVJ; LANZAR EA; ECHEVERRIA LCR; CAVALLAZZI MR; MORAES O. 1984. Adubação para a cultura da cebola na região do Alto Vale do Itajaí, Santa Catarina. Florianópolis: EMPASC. 17p. (EMPASC, Boletim Técnico, 26).

MAGALHÃES JR. Nutrição mineral da cebola. In: CHURATA-MASCA, MGC; CANALEZ, JI. 1988. Seminário Nacional da Cebola, 3. Anais. Jaboticabal-SP: ESALQ. p.93-118.

MALAVOLTA E. 2006. Manual de nutrição mineral de plantas. São Paulo: Editora Ceres Ltda. 638p.

MAROUELLI WA; ABDALLA RP; MADEIRA NP. 2008. Irrigação de cebola em sistema de plantio direto. Revista Plantio Direto 105. Disponível em: http://www.plantiodireto.com. br. Acessado em 10 de outubro de 2012

MAY A. 2006. Desempenho de hibridos de cebola em função da população de plantas e fertilização nitrogenada e potássica. Jaboticabal-SP: UNESP. 2006. 142p. (Tese doutorado).

MINISTÉRIO DA AGRICULTURA, ABASTECIMENTO E REFORMA AGRÁRIA - MAARA. 1995. Diário Oficial da República Federativa do Brasil. Brasilia: Seção 1: 13513. (Portaria n. 529).

PINHEIRO EFM; PEREIRA MG; ANJOS LHC. 2004. Aggregate distribution and soil organic matter under different tillage systems for vegetable crops in a Red Latosol from Brazil. Soil and Tillage Research 77: 79-84.

PÔRTO DRQ; CECÍLIO FILHO AB; MAY A; VARGAS PF. 2007. Acúmulo de macronutrientes pela cultivar de cebola "Superex" estabelecida por semeadura direta. Ciência Rural 37: 949-955.

RESENDE GM; COSTAND. 2009. Produtividade e armazenamento de cebola (Allium Cepa L.) submetida a doses de nitrogênio e potássio via fertirrigação em cultivo de verão. Ciência Agrotécnica 33: 1314-1320.

RESENDE GM; COSTA ND; PINTO JM. 2008. Produtividade e qualidade pós-colheira de cebola adubada com doses crescentes de nitrogênio e potássio. Horticultura Brasileira 26: 388-392.

RODRIGUES AG. 1992. Idade de mudas e doses de nitrogênio influenciando a bulbificação da cebola (Allium cepa L.) no cultivo de verão. UFV. 77p. (Dissertação mestrado). 
SÁ GD; BARTH G; REGHIN MY; CAIRES EF. 2004. Influência de doses épocas de aplicação de nitrogênio na produção e pós-colheita da cultura da cebola. In: CONGRESSO BRASILEIRO DE OLERICULTURA 44. Horticultura Brasileira 22: Suplemento CD-ROM.

SÁ JCM. 1999. Manejo da fertilidade do solo no sistema plantio direto. In: SIQUEIRA JO; MOREIRA FMS; LOPES AS; GUILHERME LRG; FAQUIM V; FURTINI NETO AE; CARVALHO JG (eds). Interrelações fertilidade, biologia do solo e nutrição de plantas. Lavras: Sociedade Brasileira de Ciência do Solo/UFL. p.267-319.

SCHMITT DR; SANTOS SC. 2009. Cebola. In: Síntese anual da agricultura de Santa
Catarina 2008-2009. Florianópolis: Epagri/ Cepa. p. 66-69.

SINGH J; DHANKHAR BS. 1991. Effect of nitrogen, potash and zinc on storage loss of onion bulbs (Allium cepa L.). Vegetal Science 18: $16-23$.

TEDESCO MJ; GIANELLO C; BISSANI CA; BOHNEN H. 1995. Análise de solo, plantas e outros materiais. 2.ed. Porto Alegre: UFRGS. 174p. (Boletim Técnico, 5).

VAZ APA; SANTOS HP; ZAIDAN LBP. 2004. Floração. In: KERBAUY GB. Fisiologia Vegetal. Rio de Janeiro: Editora Guanabara Koogan S.A. p. 366-385.

VIDIGAL SM. 2000. Adubação nitrogenada de cebola irrigada cultivada no verão: Projeto Jaíba, Norte de Minas Gerais. Viçosa: UFV. 136p. (Tese doutorado).

VIDIGAL SM; PEDROSA MW; FONSECA MS; SANTOS IC. 2010. Adubação com nitrogênio em cobertura na produção de cebola. In: CONGRESSO BRASILEIRO DE OLERICULTURA, 50. Horticultura Brasileira 28: Suplemento CD-ROM.

WIEDENFELD R; BRAVERMAN M. 1991. Fertilizer nitrogen sources for vegetable production. Subtropical Plant Science 44: 33-36.

WORDELL FILHO JA; BOFF P. 2006. Doenças de origem parasitária. In: WORDELL FILHO JA; ROWE E; GONÇALVES PAS; DEBARBA JF; BOFF P; THOMAZELLI LF. Manejo fitossanitário na cultura da cebola. Florianópolis: Epagri. p.19-162. 